\title{
JOSE CLEMENTE OROZCO. EN TORNO A LAS "CARTAS A MARGARITA"
}

TERESA DEL CONDE

Después de un año intenso de actividades dedicadas al centenario del nacimiento de Diego Rivera resulta refrescante volver a ocuparse de Orozco. Me mueve a hacerlo un hecho comprobado: en tanto que el insigne guanajuatense representa para la joven plástica mexicana un fenómeno histórico, la vigencia estética de Orozco resulta incontrovertible. Se siguen analizando sus murales que siempre dicen algo nuevo, susceptible de ser retomado. Su postura, nihilista y anarquista como lo fue, compagina con la época de crisis ya crónica que estamos viviendo, pero sobre todo es su modo de configurar, brutal y sin concesiones, lo que lo sitúa dentro de una contemporaneidad que ahora llamamos postmoderna a falta de una mejor denominación para un periodo en el que los idesales del modernismo han dejado de operar.

Este breve escrito no trata tal tipo de puntos. El pretexto inmediato para volver a ocuparme de Orozco me lo proporciona la aparición de sus cartas a Margarita Valladares, de las que la Editorial Era ha publicado una selección de doscientas cincuenta y nueve cuidadosamente editadas por Tatiana Herrera Orozco, la nieta del artista, que también preservó para la posteridad algunos recuerdos de su abuela Margarita incluyendo además unas cuantas cartas que Orozco escribió a Lucrecia su hija, la madre de Tatiana. ${ }^{1}$ De antemano diré que el material reunido no alcanza el interés de la Autobiografía, ni el de los textos reunidos por Justino Fernández, reeditados en 1983 con una addenda mía que incluye algunos más. ${ }^{2}$ Las cartas a Charlot que reunió y prologó Luis Cardoza y Aragón, así como las que incluye en su monografía, son también importantísimas como testimonios de la personalidad estética de este gran creador y contienen expresiones y pensamientos singularmente ricos, además de girones interesantísimos de sus contradicciones internas y de sus capacidades polémicas, y otro tanto sucede con las reunidas por Alvar Carrillo Gil. No pasa lo mis-

${ }^{1}$ José Clemente Orozco, Cartas a Margarita, con un prólogo de Margarita Valladares de Orozco. Presentación, selección y notas de Tatiana Herrero Orozco. Editorial Era, México, 1987

"Textos de Orozco, Recopilación, estudio y apéndice de Justino Fernández. Addenda de Teresa del Conde, Instituto de Investigaciones Estéticas, UNAM, México, 1983 
mo con las cartas a Margarita, que funcionan más bien como la entretela del conjunto de sus demás escritos, tanto de aquellos que destinó a la luz pública como de los que conforman su extensa correspondencia personal, pero no necesariamente íntima. En la medida en que Orozco pudo y quiso ser íntimo a través de sus cartas lo hizo con su mujer, sin que con ello haya demostrado la necesidad de expresar a través de la letra sus más recónditos pensamientos, salvo en las primeras cartas que le dirigió, en las que le declara su amor y en las que se centra el contenido de este artículo.

A pesar de la contención que priva en sus escritos privados, pienso que todo lo que salió de la mano de Orozco es digno de ser preservado y que su mujer, su hija y su nieta obraron con plena conciencia histórica al decidirse a dar a luz este conjunto de cartas de las que hay algunos fragmentos (pocos en verdad) que ya conocíamos gracias a otra labor editorial de gran relieve que merece todo tipo de encomio: se trata de la que realizó Clemente Orozco Valladares a través de un libro de indispensable consulta: Orozco, verdad cronológica, publicado por la Universidad de Guadalajara. ${ }^{3} \mathrm{Si}$ a esto se suma la Iconografía Personal reunida por Alba Rojo para la publicación del Fondo de Cultura Económica que reúne entrevistas hechas a varias personas por Cristina Pacheco, ${ }^{4}$ obtendremos el contrapunto perfecto para alcanzar una idea aproximada del ser humano que fue José Clemente Orozco. ¿Importa en realidad adentrarse en estos aspectos de su persona? Las opiniones se dividen. Habrá quienes postulen que basta y sobra con su obra y es absolutamente cierto, pero ésta se abre a un mayor número de lecturas a través de las posibilidades complementarias que proporcionan otro tipo de testimonios.

Orozco conoció a Margarita Valladares, hija de oaxaqueños, en Orizaba durante la primavera de 1915. Ella tenía dieciséis años y él treintaiuno. Para entonces varias cosas dignas de mención le habían acontecido. Cator ce años antes, el 14 de mayo de 1901, sustentó examen de perito agrícola en la Escuela Nacional de Veterinaria de San Jacinto con una tesis que versa sobre las f́ibras vegetales: "Nunca me interesó la agricultura - dicey jamás llegué a ser un perito en cuestiones agrarias, pero la educación y las enseñanzas que recibí en esa magnífica escuela fueron de mucha utilidad, pues el primer dinero que gané en la vida fue levantando planos

\footnotetext{
${ }^{3}$ Clemente Orozco Valladares, Orozco, verdad cronológica, Departamento Editorial de la Universidad de Guadalajara, Guadalajara, 1983.

${ }^{4}$ Orozco. Iconografía personal, Selección de fotogtafías pot Alba Rojo, Entrevistas por Cristina Pacheco, Fondo de Cultura Económica, Méxíco, 1983.
} 


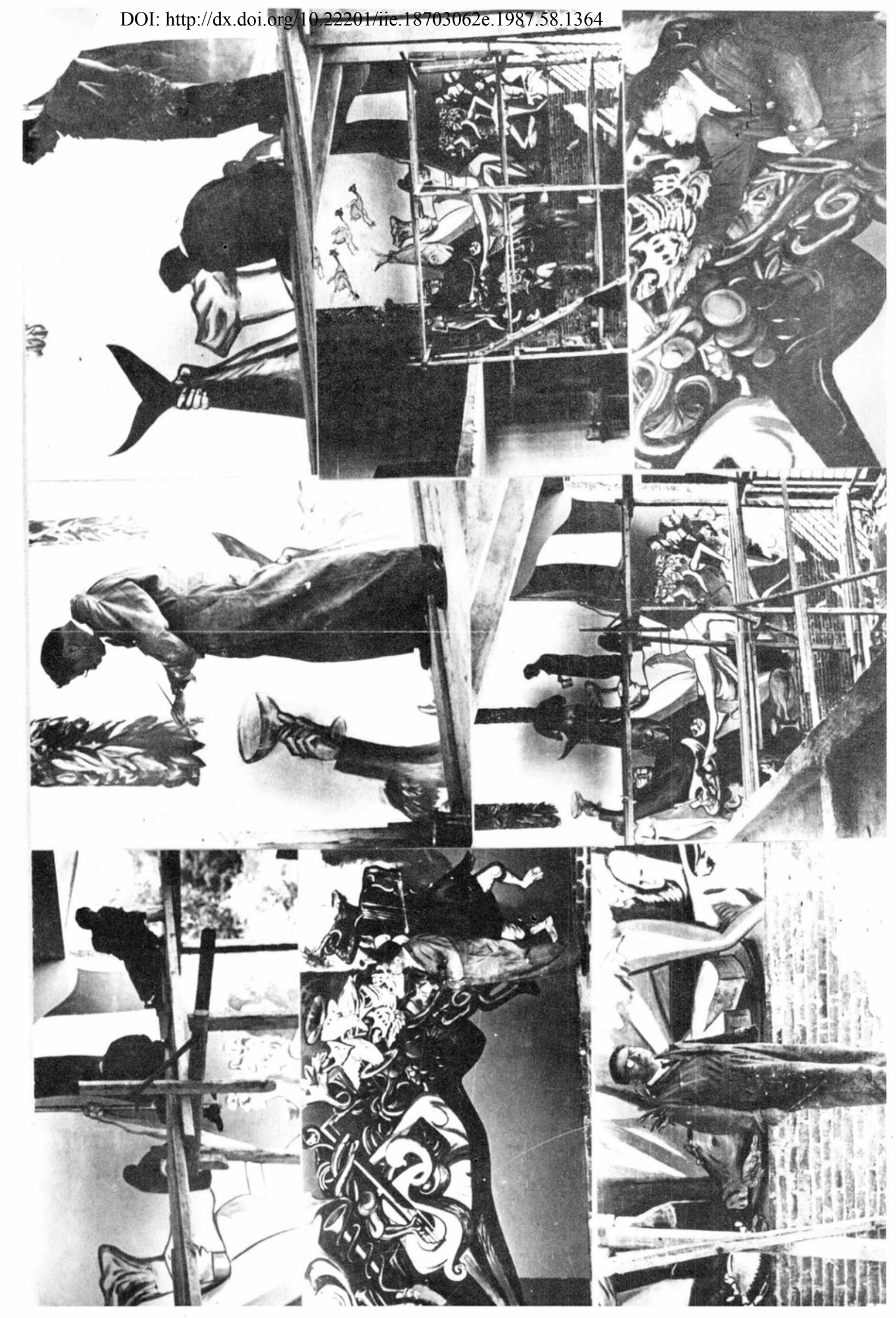


topográficos... Tres años de vida en el campo, sana y alegre..." Su entrenamiento para levantar planos coadyuvó a su entendimiento del espacio atquitectónico, que llegó a manejar con rapidez y pericia. Durante toda su trayectoria, Orozco habría de considerar el espacio como aliado por antonomasia y como eje principal de la obra mural. Así, aunque jamás volvió a plantar alfalfa ni a trazar surcos con el arado, los conocimientos aprendidos en San Jacinto dejaron un sustrato que de ningún modo fue peso muerto. Si en algo se singulariza la personalidad artística de Orozco, es en su perenne proclividad a aprovechar todas sus experiencias y de sacarles partido, acaso sin que él se diese plena cuenta de que así le sucedía. Otro hecho importante: Ireneo su padre, hombre distinguido y de muy buen ver a juzgar por las fotografías, falleció de tifo el 13 de febrero de 1903. Orozco contaba entonces escasos veinte años. Vivían en la plazuela de San Sebastián y él terminaba entonces sus estudios de preparatoria, que concluyó con medalla de oro y felicitaciones del Presidente Díaz y de su Secretario de Justicia e Instrucción Pública, Justino Fernández, a quien la sociedad porfirista tenía muy en alto. Las viejas familias mexicanas hablaban de "el ministro" y lo recibian con frecuencia en sus casas; dicho funcionario porfirista fue padre del historiador del arte, doctor Justino Fernández, concebido cuando su progenitor contaba avanzada edad. No hace falta añadir aquí que el papel protagónico del doctor Fernández en la vida profesional de Orozco, a quien admiró como a nadie, fue decisivo, lo mismo que el de Luis Cardoza y Aragón. Orozco se enfrentó pues desde los veinte años a una responsabilidad familiar que ya jamás lo abandonó y que lo entrenó para sus posteriores deberes como padre y esposo. Se hizo cargo completo de su madre, doña Rosa Flores, y de sus hermanos Rosa y Luis, a pesar de que al año siguiente (1904) sufrió el mayor trauma de su vida al perder la mano izquierda debido al atraso que en cuanto a asepsia privaba en los hospitales de México. Al estar experimentando con pólvora se le afectaron gravemente los dedos; lo atendieron en el Hospital San Lázaro y desarrolló gangrena a los pocos días; por tal razón le amputaron la mano hasta la muñeca. Los traumas capaces de incidir en la personalidad de un individuo para toda la vida son sólo de dos tipos: o provienen de la infancia temprana (hasta los cinco años aproximadamente) y devienen en parte inconscientes, pero efectivos para el ulterior desarrollo de la personalidad, o son traumas que entrañan un tremendo impacto físico: encontrarse sepultado entre los escombros de un terremoto, sufrir un accidente severo en el

${ }^{5}$ José Clemente Orozco, Autobiogratia, Editorial Era, México, 1981, Segunda edición, p. 15 
que se esté a punto de perder la vida, y sobre toda la mutilación. De la lesión sufrida jamás se repuso Orozco, a pesar de todos los mecanismos de sobrecompensación que desarrolló a partir de entonces y que potenciaron su creatividad en grados insospechados. Entran aquí de lleno los testimonios legados en las cartas a Margarita. En la primera encontramos el ejemplo contundente por antonomasia:

Hace muchos años que guardo en mi corazón un sentimiento que ha sido hasta hoy dominado por mi voluntad y por el sufrimiento de ver mi cuerpo destrozado y lo ridículo y desagrabilísimo de mi persona. ${ }^{6}$

Ver su cuerpo destrozado... Y por ello abstenerse por años de declarar su amor a la joven elegida. Estas líneas van en contraposición de lo que leemos en la Autobiografía: "la perdí cuando era muy joven, jugando con pólvora; un accidente como otro cualquiera". ${ }^{7}$ Pero las cartas a Margarita precisamente demuestran que el efecto del trauma nunca cesó, ni podría cesar. No nos encontramos ante un hecho del tipo Cessante causa cessat effectus. No se trata de un trauma de aquellos que los psiquiatras denominan "banales" (y que en todas formas, unidos a experiencias preexistentes, son capaces de desarrollar intensas neurosis), sino del cercenamiento irreversible de una parte importante del cuerpo. A la minusvalía física se añadió el horror y al horror la fuerte lesión infligida a la estética corporal. Frida Kahlo, muy enferma física y psíquicamente, no llegó a desintegrarse sino hasta que le amputaron la pierna, cosa que ocurrió cuando contaba cuarenta y seis años. Su situación no es comparable a la de Orozco más que en un sentido: también ella experimentó una intensa afrenta estética y una castración simbólica que precipitó su muerte. Orozco adolescente y con un yo seguramente más fuerte pudo desarrollar formidables mecanismos de sobrecompensación que, como he anotado, potenciaron y acaso determinaron en gran medida sus índices creativos, pero el complejo de mutilado allí se quedó, actuando en forma activa durante su juventud y madurez temprana y mitigándose a medida que alcanzaba fama y reconocimiento. Otro caso es el del Dr. Atl, a quien una perenne condición hipomaniaca defendió contra la minusvalía. Hay que pensar también en los impedimentos físicos de Orozco, por más que sus hijos insisten en que jamás notaron su condición de manco: simplemente la mano no estaba allí y no se hablaba del asunto ni se le preguntaba cómo la había perdido; hay que interpretar el silencio como denegación. Importaba tanto esa carencia que fue can-

${ }^{B}$ Cartas a Margarita, p 73

'Autobiografía, p. 34. 
celada en el discurso y en el acontecer cotidiano. No así en las cartas. En varias se queja con Margarita porque escribir le cuesta demasiado trabajo, a veces le duele el brazo derecho después de las sesiones exhaustivas a las que se sometía cuando estaba pintando alguna obra mural. El 16 de octubre de 1929 se queja de las múltiples cartas que ha tenido que escribir: "es para mí un verdadero problema y un suplicio" y de que tiene que trabajar con suma rapidez para cubrir a diario y sin pausa dos metros cuadrados de fresco, "iY todo, absolutamente todo, con una sola mano!" Posteriormente, en junio de 1931, escribe a Detroit, donde Margarita y sus hijos pasaban una temporada con unos parientes y la reprocha por no entender su condición: "Ten compasión de tu marido y considéralo". En esa carta vuelve a recordarle cuatro veces que tiene sólo una mano, subrayando las palabras, y los recordatorios continúan en suçesivas cartas escritas años después durante otra estancia en Nueva York. Desde luego las funciones de la mano derecha se afinaron y fortalecieron a tal grado que la esposa efectivamente llegó a considerar que su condición de manco era un hecho perfectamente superado, equivalente al del miope que tiene que usar anteojos. Dice Margarita a su nieta Tatiana: "A tal modo era perfecto su dominio de la mano derecha que jamás se comentó el accidente en la familia, porque simplemente no notábamos que le faltara, aun y cuando lo supiéramos". $\&$ Añade Clemente, su hijo, que nadie ha prestado atención a la espléndida forma que desplegaba Orozco al pintar manos relacionándola con el malhadado acontecimiento. Cosa inexacta; en lo que toca a mí puedo no sólo decir sino demostrar que he escrito sobre la sobrecompensación creativa en Orozco, y que además me he referido al poderoso impacto de las manos en muchas figuras suyas, a las ilustraciones de un libro y a la gran mano fálica con dedos suplementarios realizada en piroxilina el año de 1948."

Esta imagen me sirvió en una ocasión para ilustrar las investiduras que se presentan en el complejo de castración.

Retorno ahoxa al año de 1915 en que Orozco vio por primera vez a Margarita en Orizaba, donde llegó el mes de febrero con el grupo que fundaría el periódico La Vanguardia. Dice Margarita a su nieta:

Con este fin solicitó la colaboración de un grupo de personas calificadas, de valer, entre las que figuraban escritores, periodistas, artistas, etcétera.

* Orozco, verdad cronológica, p. 35.

9 Teresa del Conde "Sobte la personalidad de Orozco". En Jorge Alberto Mantique et al., Orozco, una reelectura, Instituto de Investigaciones Estéticas, UNAM, México, 1983 , pp. 25 a 61 
Tu abuelito y tu tío Francisco, mi hermano, se encontraban en dicho grupo... Entre mi hermano y tu abuelito existía también un conocimiento previo, porque habían sido condiscípulos en la Escuela Anexa a la Normal de Maestros en la ciudad de México, lo cual ocurrió alrededor del año de 1901. Algunos de estos colaboradores llevaron a su familia a Orizaba como fue el caso de mi hermano Francisco. ${ }^{10}$

Se alojaron en una casa de la calle de Corina, tanto la familia Valladares como el equipo del periódico que se integraba, según anota Orozco en su Autobiografia de las siguientes personas. Director: el Doctor Atl. Jefe de redacción: Raziel Cabildo. Taquigrafía: Elodia Ramírez. Redactores: Juan Manuel Giffard, Manuel Becerra Acosta, Francisco Valladares, Luis Castillo Ledón y Rafael Aveleyra. Dibujantes: Miguel Ángel Fernández y Romano Guillemín. Grabador: Tostado. Consejero de arquitectura: Francisco Centeno. Caricaturista: Clemente Orozco. Dobladoras: "las muchachas hijas de las familias de nuestro grupo, todas hermosas, destacándose muy especialmente Josefina Rafael por su exquisita belleza". Aclara a continuación que Alfaro Siqueiros (no mencionado antes) y Francisco Valladares fueron enviados de La Vanguardia cerca del general Diéguez, que combatía el villismo en Jalisco: "Todos vivíamos en una casa incautada que había sido convento y suficientemente grande, tanto para los que tenían familia como para los solteros. Se le puso por nombre La Manigua". ${ }^{11}$ Para entonces la trayectoria de Orozco como caricaturista estaba bien cimentada. Se inició en 1906 y todavía en 1924, cuando lo ahuyentaron de San Ildefonso, era más conocido en el ambiente periodístico que en el de la pintura. Fue colaborador de El Ahuizote, el ABC, El Heraldo, Acción Mun dial, la revista Orbeal que dirigia Raziel Cabildo, y desde el 18 de julio de 1914 dirigió un periódico dedicado específicamente a la caricatura. Se trata de El Malora, que muy pocos han podido localizar. Clemente Orozco Valladares reproduce páginas de algunos ejemplares en Orozco verdad cronológica. ${ }^{12}$

Margarita relata a su nieta:

Había puesto Atl una ama de llaves para que nos atendiera y nos diera los alimentos. En varias ocasiones, sentados a la mesa, quedaba yo frente a tú abuelito. A esta circunstancia se refirió él en una de las cartas que me escribió posteriormente. ${ }^{13}$

10 Cartas a Margarita, p. 13.

11 Autobiografía, pp. $44-45$

1.2 Orozco, verdad cronológica, pp. 54 y s

i3 Cartas a Margarita, p. 14 
Veamos qué dice Orozco al respecto:

Recordé el despertar de mi alma allá en Orizaba, recordé mi resigna ción y mi penosísimo esfuerzo por ocultar mi naciente sentimiento y la honda y dulcísima simpatía que Ud. me inspiró, convertida ahora sin sentirlo ni sospecharlo yo en un amor violento, doloroso y sin esperanza. ${ }^{14}$

Si se toma en cuenta que en 1915 Orozco le duplicaba la edad a Margarita, es de suponerse que aquel encuentro no pasó de ser una imagen de las que dejan huella. No entablaron amistad en Orizaba, conversaron sólo en una ocasión en que Orozco pidió a Margarita que le posara para un estudio ide manos! A ella le sorprendió su presencia (se encontraba divirtiéndose con sus hermanas y con la hermosa Josefina Rafael en el campanario de la iglesia de Dolores) y más aún le desconcertó que le pidiera que posara. Mientras Orozco dibujaba sus manos tuvieron una conversación bastante convencional que Margarita intenta reconstruir. Dice que su extrema juventud le "impidió ahondar en la observación de su personalidad, pero recuerdo que en ese momento se mostró lo sociable que comúnmente no era. ..". Su presencia le infundió "mucho respeto". ${ }^{15}$

Desgraciadamente esos dibujos de las manos de Margarita se han perdido o no ha sido posible localizarlos. A juzgar por el apunte de medio cuerpo que Orozco le hizo en 1942 y en el que el brazo izquierdo flexionado ocupa el primer término, Margarita tenía (tiene) manos grandes, posiblemente fuertes. Eso es mera suposición, pues Orozco rara vez fue dibujante naturalista y además - por razón lógica - tuvo la tendencia a realzar la importancia de las manos. Un dibujo más del mismo año, en el que sólo aparece la cabeza de Margarita vista de perfil, deja entrever el puño y la mano apenas bocetada en su contorno externo, fina y alargada, que se apoya en la barbilla. Para otra persona en quien depositó afecto amoroso, Gloria Campobello, Orozco ilustraría muchos años más tarde un libro con dibujos de manos. Por cierto, las Cartas a Margarita dan cuenta -una vez más por omisión tipo denegaciỏn- del vínculo efímero que mantuvo Orozco con la bailarina y coreógrafa que junto con su hermana Nelly desempeñó importante papel en la renovación de la danza en México, tal y como se desprende de un artículo de largo título publicado el 21 de marzo de 1945 en Excélsior, cuyo autor es Orozco mismo. ${ }^{16}$ Hay

14 Ibidem, p. 73.

15 Ibidem, pp 14-15.

16 José Clemente Orozco, "No es una improvisación el ballet organizado aquí, lo estuvieron preparando 10 años y es una 'realidad indestructible" "Excélsior. México, marzo 21 de 1945. También en Textos de Orozco, pp. 67-69. 
una carta a Margarita que deja entrever el asunto Campobello. Orozco en esa ocasión permaneció en Nueva York desde el 15 de septiembre hasta el 14 de matzo del año siguiente. Los primeros meses también estuvo allí Gloria Campobello, pero sin compartir la misma vivienda; al parecer, ella iba acompañada por otra persona. El plan de Orozco era permanecer en Nueva York mucho más tiempo, pero ni sus proyectos con galerías, ni su relación con la Campobello cuajaron. El párrafo de dicha carta a Margarita revela el ocaso de su aventura:

Ya no me importa [estar en Nueva York]; no me interesa ya sino estar tranquilo y en paz a tu lado. Ya sé que me he portado muy mal contigo, ya lo sé, bien caro lo pago con mi remordimiento, pero algún día llega la luz de la Verdad a enseñar qué es lo verdadero y qué lo falso. ${ }^{17}$

Esa carta, a diferencia de las escritas a partir de septiembre, que terminan con un saludo cortés, pero bastante seco y abrupto, se rubrica con un "te adora". La inmediatamente anterior, del día 5, pide a su mujer que le escriba con su bonita letra de antes, pues la extraña, "yo sé que no lo merezco, pero alguna vez me has de perdonar". ${ }^{18}$

Fuera del affaire Campobello, de una posible querencia con Alma Reed, debida a la extrema soledad en que se encontró durante los inicios de su larga etapa neoyorkina y de una que otra galantería con las damas que trabajaban en "las casas de magnífica nota" mujeres que le interesaron como temas de arte, pero también como seres humanos- es poco probable que Orozco haya tenido otros amoríos. Por cierto, la tendencia a vincularse con mujeres supuestamente degradadas en pequeños encuentros pasajeros, es muy característico de los hombres que se sienten minusválidos en las lides del amor. En cualquier forma, su entrega casi sacerotal al arte, su carácter medio ascético, su sentido de responsabilidad conyugal y familiar, lo mantuvieron junto a Margarita desde que se casó con ella el $1^{\circ}$ de diciembre de 1923 , previo noviazgo de dos años, hasta que murió inesperada pero tranquilamente en su casa de Ignacio Mariscal el 7 de septiembre de 1949.

La primera carta de amor es, como he dicho, el punto de partida para este artículo. Vuelvo a ella para especificar algunas de sus características. Orozco poseía "la audacia en tromba de los tímidos", según sabia frase de Luis Cardoza y Aragón. ${ }^{19}$ Por eso, aunque jamás había abordado a

${ }_{17}$ La carta está fechada en Nueva York el 9 de diciembre de 1945

18 Cartas a Margarita, p 332

19 Luis Cardoza y Aragón, "Dos apuntes para un retrato". En Orozco, una realectura, p. 12 
Margarita en el tren que hacía el recorrido entre Coyoacán y el Zócalo (am. bos vivían en Coyoacán y trabajaban en el centro de la Ciudad), le espera con frenesí desbordado: "la amo... la adoro locamente, ciegamente, con delirio, con toda mi alma, con todo mi ser. iLa amo a Ud., Margarita bella!" La timidez se mantuvo en los encuentros en el tranvía: Orozco se limitó a hacer el ademán de levantarse el sombrero a modo de saludo aunque conocía a Hortensia Valladares, por supuesto a Francisco y desde luego a la propia Margarita. Por escrito, distanciado de la presencia física del objeto de amor elegido, hizo su declaración que no se diferencia mucho de otras, apasionadas, que encontramos en las correspondencias publicadas de escritores, poetas y hombres famosos.

Para 1921 Orozco ya contaba con alguna seguridad económica. El problema de su familia de origen estaba resuelto. Desde 1903 junto con su hermano Luis compró un amplio terreno en la calle Madrid. Allí edificó una casa para que viviera su madre: doña Rosa Flores, junto con la familia de Luis. El mismo año de su declaración amorosa comenzó a construir su estudio independiente, al que poco después le adhirió su primera casa habitación propia. Debe haber sido un terreno hermoso, como los que hasta hoy en día se conservan en algunas casas de Coyoacán: una pequeña huerta. Margarita lo recuerda así:

Tenía nuestro terreno cuatro enormes pinos, un tejocote muy frondoso en el que habían injertado tres variedades de peras, un capulín, una mora de frutos riquísimos, un chabacano injertado de ciruelo y, junto al estudio, una higuera que sobrepasaba el techo del propio estudio. Todos estos árboles daban fruta abundante y deliciosa. ${ }^{20}$

¿Por qué se enamoró Orozco de Margarita? En primer lugar, porque su situación le permitía augurar que podía ser correspondido. Tenía que garantizar con algo su propuesta y ya estaba en condiciones de hacerlo. Margarita se encontraba, hasta cierto punto, a su alcance: provenía de una familia que satisfacía sus aspiraciones éticas, era una muchacha extraordinariamente seria (el opuesto total de las damas que Orozco conocía allá por las calles de Licenciado Verdad), y además, le parecía físicamente atractiva. Hay pocas fotografías que nos entreguen su apariencia por esos años, pero basta una, publicada por desgracia a escala muy reducida en la p. 138 de Orozco, verdad cronológica. Es una foto de ovalito tomada probablemente cuando ella tenía unos veinte años. No se perciben las líneas de sus hombros ni del busto, pero sí el cuello y el arranque de los

21) Cartas a Margarita, p. 16 
hombros. A través de lo que la pequeña foto revela, se diría que la muchacha era bastante atractiva: ojos oscuros rasgados, cejas de fino trazo, boca bien dibujada de labios llenos, incluso sensuales, frente amplia sobre la que cae un coqueto rizo. En fotografías posteriores en las que aparece de perfil es posible percibir la nariz algo respingona y la línea firme de la barba. Cuando Orozco le dice "Minita" está aludiendo a su bonitura y acaso a cierto carácter felino que veía en ella. Por cierto que le gustaban mucho los gatos, les decía "tonches" y pregunta en especial por uno a quien manda saludar en las cartas que escribe a Lucrecia, la que a su vez envía la foto de este gato predilecto. Le gustaban, dice Lucrecia, por sus movimientos y por su elegancia, pero sobre todo porque no hacían ruido. A Orozco le era imprescindible el silencio cuando estaba trabajando. Mientras pintaba destestaba que lo interrumpieran. "Esa fue la razón de que jamás hayamos tenido un aparato de radio", confiesa la misma Lucrecia. Sin embatgo sí disfrutaba la música, asistía a conciertos y escuchaba a Bach, a Beethoven y a Mozart, pero jamás cuando se encontraba pintando o dibujando. Margarita era seria, silenciosa y respetuosa. Probablemente nunca fue una buena interlocutora, más que en cuestiones prácticas. Orozco no le habla de su pintura ni le descubre su proceso creativo, como sucede, por ejemplo, con James Joyce y Nora Barnacle; a través de lo que Joyce le escribía es posible vislumbrar las entretelas de la creación. Aquí no hay eso.

Después vinieron los "rorros" (tres hijos) y la calma callada lógicamente se acabó. Es posible que algunos de los periodos largos en que la familia vivió separada se debieran - en cierta medida - a que Orozco no era capaz de compartir su vida creativa con el natural bullicio de la vida familiar, sobre todo cuando los niños se encontraban en la infancia temprana. En alguna ocasión Juan O'Gorman me comentó (no sé si la anécdota sea cierta) que Orozco les pagaba a sus hijos para que se callaran y se estuvieran quietos. De hecho, su desarrollo profesional marcó la evolución y el destino ulterior de su familia. Su exorbitada necesidad de cumplirse a sí mismo como artista estuvo por encima de su vida afectiva, sin que ello implicara ni desentendimiento ni irresponsabilidad. Simplemente lo primero era el arte. Raquel Tibol lo definió certeramente en una mesa redonda celebrada con motivo de la publicación de estas cartas: "Era como un sacerdote concentrado en su celebración artística, dispuesto a sacrificar todo para llevarla a cabo".21

${ }^{21}$ Presentación del libro José Clemente Orozco. Cartas a Margarita Mesa redonda con Tatiana Herrero Orozco, Jorge Alberto Mantique, Raquel Tibol y Teresa del Conde Museo de Arte Moderno, México, mayo 12 de 1987. 
En diferentes momentos de su vida Orozco retrató a su mujer. El cuadro más conocido es un temple sobre tela hecho en 1938, seguramente en Guadalajara. Ella tendría entonces unos treinta y nueve años, sus rasgos son firmes y todavía juveniles, aunque su expresión es adusta. Ni con ella hizo Orozco concesiones. Su mujer padecía de un ligero estrabismo - pero no crónico-- que en la pintura es muy patente. El cuadro es energético, pero no tan acabado como el de la señora Sikelianos, ni tan fuerte como el de Celia Chávez de García Terrés, única dama, además de Nancy Nancarow, a quien Orozco pintó atractiva. De hecho, en 1934 él mismo asevera que le es muy difícil pintar a una mujer hermosa; lo hace a propósito de un retrato de encargo cuya modelo fue la señora Weiztner: "Es un retrato difícil por tratarse de una mujer joven y bonita, pues en este caso es fácil caer en trivialidades, pero quedó fuerte y bien pintado". ${ }^{22} \mathrm{El} \mathrm{ma-}$ rido de la Weiztner fue un dealer muy acaudalado que hizo todo lo posible por conseguir que Orozco pintara un mural en La Porte, sitio donde tuvo una exitosa exposición. Por esa pintura, haciendo una rebaja cobró doscientos cincuenta dólares en el año de 1934, misma fecha en que el Museo de Baltimore le compró un dibujo por cien. Casi la totalidad de las cartas a Margarita son pródigas en observaciones de carácter económico que llegan a volverse enojosas para el lector, pero que arrojan datos sobre muchos factores en los que no solemos pensar cuando reflexionamos acerca de la creación artística. El mercado del arte es uno de ellos, y no el menos importante. Por ejemplo, al año siguiente de su llegada a Nueva York, y ya con Alma Reed como representante suya, vende una litografía en 500 , pero esto acontecía muy de vez en cuando, además de que Orozpagado sólo 13. En cambio, al poco tiempo Alma Reed le vendió un óleo en 500, pero esto acontecía muy de vez en cuando, además de que Orozco estaba obligado, de alguna manera, a prestar dinero para los fondos de la galería que ella y Eva Sikelianos abrieron con el propósito primordial de difundir su obra. Así, su situación económica durante la primera fase de su vida neoyorkina fue sumamente angustiosa. Tenía que alimentar su propia producción y la mayor parte de sus ganancias se destinaban a eso. A la vez, su manutención naturalmente le suponía erogaciones, por mâs parca que su conducta fuera, y el hecho de mantener de lejos a su familia era una preocupación primordial, con la que cumplía lo mejor que podía; además, nunca dejó de enviarle pequeñas cantidades a su madre. Confiaba en Margarita para solicitarle (e incluso exigirle) actividades tales como localizarle ciertos colores, llevar ejemplares de libros o catá-

22 Cartas a Margarita, p. 279 
logos a determinadas personas, supervisar que las fotografías que mandaba tomar de sus murales en México se procesaran en poco tiempo y le fueran enviadas de inmediato, etcétera. Margarita, que debe haberlo visto como a un dios del Olimpo a quien nada puede negarse, cumplía con estos encargos con la presteza y solicitud que sus capacidades y sus ocupaciones como madre de familia le permitían. Años más tarde asumió plenamente su papel de representante de Orozco y era ella quien daba la cara ante marchands, galeristas, editores, etcétera. Puede decirse que vivió largas temporadas de su vida completamente supeditada a las órdenes de ese Prometeo manco capaz de bombardear con órdenes y recomendaciones, pero a la vez susceptible de mostrarse tierno.

La pasión expresada en la carta primera se prolonga en las inmediatamente subsecuentes:

Yo sólo sé que la amo, Margarita, sólo sê eso, ¿qué sabe mi corazón de nada más?.. . Déjeme usted soñar, déjeme usted adormecido en mi azul ensueño de amor y poesía. . . Mi alma es demasiado complicada; es un inmenso bosque en donde no penetra el más tenue rayo de luz, es una maraña que nunca he podido desenredar, es una fantástica gruta formada de piedras preciosas, envuelta en sombras impenetrables y temibles, es como una débil planta que se estremece a la más ligera brisa y también es como arma de fino acero que mata y que destruye ciegamente. . "Yo no sé cómo soy, sólo sé que la amo, Marganita idolatrada!. . . 23

Después del matrimonio las cosas cambian. La "linda y graciosa Margarita de mi corazón" se convierte en "Miti querida", "Pipirilisti", "Bisti", "queridísima mujercita". Sin embargo Orozco la extraña y así se lo manifiesta, sobre todo en los momentos en que está extremadamente solo y no puede entregarse de lleno a sus impulsos creativos. Cuando esto ocurre se vuelve optimista y exultante, ningún sacrificio le parece poco. Su verbosidad amorosa, expresada aquí y allá en frases cortas de saludo y despedida, es escueta y la autoconfesión profundamente introspectiva y descarnada que lo autorretrata con el mismo doble filo que poseen sus pinturas, desaparece del todo. En lo que hizo pintando están los pares de opuestos, las gemas preciosas, las cavernas, la luz, el rayo y el trueno. Si se quiere desentrañar al hombre José Clemente Orozco, no ya digamos al Orozco artista, a la obra hay que acudir primero. Ni la Autobiografía con todo y su riqueza conceptual, ni las cartas a Charlot o a Cardoza y Aragón son testi-

Ibidem, pp $81-82$ 
monios de su sentir íntimo, aunque sí de su pensar, de su capacidad crítica, de sus antinomias y contradicciones y de su sentido del humor, un humor cáustico e irreverente que, seguramente por excesiva precaución acerca de lo que él pudo haber considerado "la dignidad de la mujer", incursiona poco en el libro objeto de este comentario. Sin embargo, los neologismos y apodos testimonian en todo momento que su capacidad de reírse de sí mismo y de los demás se mantuvo de principio a fin. Esto atenúa la mor-dacidad de sus frases ofensivas (frases de "perro que ladra no muerde"), emitidas sobre todo a propósito de Diego Rivera, a quien en el fondo admiraba como pintor, según reciente testimonio verbal de Fernando Gamboa, ${ }^{24}$ y según lo atestiguan también algunas fotos en las que -haciendo gala de una vena humorística más - "posa" flanqueado por Diego y Siqueiros con expresión entre socarrona y de "despide-huéspedes".

No es aquí el lugar para analizar a qué grado le importaba a Orozco la fotografía, por lo que sólo remito a las numerosas cartas en las que reco. mienda incluso el ángulo desde donde deben tomarse los murales y además a la siguiente declaración: "Por cierto que en este asunto fotográfico he gastado un dineral y seguiré gastando, pero no hay otro remedio". Se está refiriendo por supuesto a lo importante que le resultaba poseer buenas fotografías de toda su obra, mismas que en el caso de que se tratara de fo. tos de murales, eran exhibidas junto con dibujos, litografías y pintura de caballete. Pero también le importaba su propia fotogenia. Sabía cómo plantarse ante un fotógrafo y la ya mencionada Iconografía personal da cuenta de ello de manera contundente. Abundar respecto a sus aptitudes como modelo (casi se diría que como actor) queda fuera de los propósitos del presente escrito. Sólo diré, acudiendo una vez más a la primera carta de amor, que "lo ridículo y desagradabilísimo" de su persona era, valga la redundancia, un problema personal. Las fotos revelan a un hombre de rasgos muy firmes, expresión interesante y con indudable persona. lidad. Es bastante más atractivo el Orozco con lentes de miope de 1921 que el joven con la frente calzada y mejillas abultadas de 1901. No existe ni en ese momento ni posteriormente nada ridículo en su apariencia, que con el tiempo fue adquiriendo una cierta comicidad, acorde al polo huraño de su carácter. Así al menos se le percibe en las fotografías. Tal cosa puede resultar engañosa porque, como he dicho, sabía posar para ellas, sobre todo si no le eran tomadas por fotógrafos artistas, como Wes.

${ }^{24}$ Fernando Gamboa le preguntó a Orozco: "Excluyéndolo a usted, ¿a quién considera el mejor pintor de México?" La bteve respuesta fue: Rivera. Fernando Gamboa y Teresa del Conde, Entrevista. Zacatecas, Zac, 18 de mayo de 1987. 
ton y Manuel Álvarez Bravo. También llegó a complacerle el autorretrato y, como de sobra se sabe, dejó pinturas espléndidas dentro de este género. Todas son posteriores a su matrimonio, por lo que es posible afirmar que el ser aceptado por la joven mujer y el convertirse en el centro de su afecto y de sus preocupaciones le hizo en parte reconciliarse consigo mismo y así se reaseguró como ser humano y como artista. Quien sepa leer entre líneas encontrará que las cartas a Margarita ayudan a perfilar con trazos más nítidos algunos aspectos de su complicada y rica personalidad, no sólo por lo que dicen, sino también y de modo muy importante por lo que callan. 